\title{
Significance of exercise induced ST segment elevation in patients with previous myocardial infarction
}

\author{
KIM M FOX, ^ ANNE JONATHAN, ANDREW SELWYN \\ From the Division of Cardiovascular Disease, Hammersmith Hospital, DuCane Road, London
}

SUMMARY In order to determine the significance of exercise induced ST segment elevation in patients with previous myocardial infarction, we have studied 156 patients, 26 months (mean) after myocardial infarction. Each patient underwent 16 lead precordial electrocardiographic mapping before, during, and after exercise and in addition coronary arteriography was performed. There was no significant difference in the extent of coronary disease or abnormalities of left ventricular function between patients with exercise induced ST segment elevation that was noted to occur in leads with $Q$ waves and those with ST segment elevation plus depression or those with ST segment depression alone. Patients without exercise induced ST segment changes had fewer coronary arteries involved than those who developed ST segment changes. Nineteen patients with exercise induced ST segment elevation alone underwent coronary artery bypass surgery; in 11 this resulted in complete abolition of the exercise induced ST segment elevation and was associated with symptomatic relief and patent grafts without alteration of left ventricular function. Thus, exercise induced ST segment elevation in patients with previous myocardial infarction should be considered as important as ST segment depression in terms of underlying myocardial ischaemia, coronary anatomy, and left ventricular function.

In recent years there has been much interest in the use of exercise testing both early and late after acute myocardial infarction. ${ }^{1-3}$ It has been shown that the development of ST segment depression with exercise is associated with a higher incidence of future coronary events. ${ }^{4}$ In such patients early venous graft surgery may be considered. Much less is known, however, about the significance of exercise induced ST segment elevation in patients with previous myocardial infarction. This study was designed to examine the clinical and angiographic findings of this electrocardiographic sign in association with previous myocardial infarction.

\section{Patients and methods}

One hundred and fifty six patients (102 men, 54 women) with a single documented previous myocardial infarction undergoing coronary angiography were studied. Ninety eight patients complained of chest pain; 72 complained of shortness of breath $(>$ NYHA

^Present address: National Heart Hospital, Westmoreland Street, London W1M 8BA.

Accepted for publication 7 October 1982 grade $2 a$ ) with or without accompanying angina. They were aged 44 to 67 (mean 54) years.

Myocardial infarction was documented by at least two of the following features: a typical history of chest pain, typical electrocardiographic changes, and a rise in serum enzymes. No patient was exercised within three months of a documented myocardial infarction. The interval between the myocardial infarction and the exercise test was $26 \pm 17$ months (mean $\pm S D$ ).

\section{EXERCISE TESTING}

Sixteen precordial electrocardiographic leads (unipolar V leads connected to a central Wilson terminal) were positioned on the chest in order to cover the left hemithorax. ${ }^{5}$ Each patient performed an increasing work load on a bicycle ergometer using a standardised procedure. The exercise tests were limited by chest pain, dyspnoea, fatigue, or multiple ventricular ectopic beats. Exercise tests were performed within one week of coronary angiography; in those patients undergoing coronary artery bypass graft surgery it was performed three to six months postoperatively. The method, sensitivity, and specificity of this technique have already been published. ${ }^{56}$ At each of the 16 positions ST segment depression or elevation was 
Table 1 Clinical details of 156 patients with previous myocardial infarction

\begin{tabular}{|c|c|c|c|c|c|c|}
\hline & & $S T \uparrow$ & $S T \downarrow$ & $S T \uparrow+S T \downarrow$ & No $S T$ & Total \\
\hline \multirow{2}{*}{ Site of infarction } & $\{$ Anterior & 22 & 46 & 12 & 17 & 97 \\
\hline & Inferior & 10 & 34 & 6 & 9 & 59 \\
\hline $\begin{array}{l}\text { Time from } \\
\text { infarction (mth) }\end{array}$ & & 23 & 28 & 25 & 24 & 26 \\
\hline \multirow{2}{*}{ Angina } & $\{$ Present & $20(63)$ & $58(73)$ & $12(67)$ & $8(33)$ & 98 \\
\hline & Absent & $12(37)$ & $22(27)$ & $6(33)$ & $18(67)$ & 58 \\
\hline \multirow{2}{*}{ Dyspnoea } & $\int$ Present & $15(47)$ & $36(45)$ & $9(50)$ & $12(46)$ & 72 \\
\hline & Absent & $17(53)$ & $44(55)$ & $9(50)$ & $14(54)$ & 84 \\
\hline
\end{tabular}

Figures in parentheses are percentages.

measured in three complexes and an average taken. ST segment changes were measured in millimetres $(\mathrm{mm})$ to the nearest $0.5 \mathrm{~mm}$. The ST segment was considered depressed if there was a change of $1.0 \mathrm{~mm}$ or more lasting $0.08 \mathrm{~s}$ or longer. The ST segment was considered raised if there was a change of $1.0 \mathrm{~mm}$ or more measured $0.06 \mathrm{~s}$ after the end of the QRS complex. The exercise tests were reported without knowledge of the clinical symptoms or results of coronary angiography.

Contour maps of the area of ST segment change were drawn for each precordial surface map. ${ }^{7}$ The 16 precordial positions were divided into three areas (anterior, inferior, and lateral) and an attempt was made to predict the coronary disease from the site of electrocardiographic changes (that is anterior=left anterior descending, inferior $=$ right, and lateral $=$ circumflex coronary disease). ${ }^{7}$

\section{CORONARY ANGIOGRAPHY}

Left ventricular angiography and selective coronary arteriography were performed using the Judkins technique. Where coronary arteriography was, in addition, performed after coronary artery bypass graft surgery this was done via a percutaneous femoral approach three to six months after direct myocardial revascularisation. In each case, the saphenous vein graft was either selectively opacified or the occluded origin visualised. The radiologist and cardiologist who performed the investigations also interpreted them without knowledge of the findings at exercise electrocardiography. Lesions obstructing the coronary artery lumen by $70 \%$ or greater were considered significant.

\section{Results}

Satisfactory recordings were obtained in all patients. The clinical details are shown in Table 1 . The relation between clinical symptoms and extent of coronary disease described at coronary angiography is shown in Table 2. It can be seen that a history of shortness of breath with or without angina was not associated with more severe coronary disease than when angina occurred alone. Nor was the site of infarction related to the extent of coronary artery disease (Table 3 ).

\section{ELECTROCARDIOGRAPHIC CHANGES}

Exercise induced ST segment elevation was found in $32(20.5 \%)$ patients; in all, the ST segment elevation occurred in the leads with previous myocardial infarction, that is those leads with $Q$ waves. A further 18 (11.5\%), in addition, developed ST segment depression in other leads. There were $80(51 \%)$ patients with ST segment depression alone in response to exercise and a further $26(17 \%)$ patients who developed no ST segment changes. It will be seen from Table 1 that all types of electrocardiographic responses were seen both in patients with angina and those with shortness of breath. Exercise induced ST segment elevation was equally common and if anything slightly more frequent in those patients with angina (32/50: 64\%) than

Table 2 Relation between clinical symptoms and extent of disease

\begin{tabular}{llll}
\hline \multicolumn{4}{l}{ Coronary disease } \\
\cline { 2 - 4 } & One vessel & Two vessel & Three vessel \\
\hline Angina & 18 & 29 & 40 \\
Dyspnoea & 14 & 18 & 37 \\
\hline
\end{tabular}

Table 3 Relation between site of infarction and extent of disease

\begin{tabular}{llll}
\hline & One vessel & Two vessel & Three vessel \\
\hline Anterior & 20 & 27 & 50 \\
Inferior & 12 & 20 & 27 \\
\hline
\end{tabular}


Table 4 Relation between electrocardiographic changes and coronary anatomy

\begin{tabular}{lcccc}
\hline Coronary anatomy & No. with & & & \\
\cline { 2 - 5 } & $S T \uparrow$ & $S T \downarrow$ & $S T \uparrow+S T \downarrow$ & No ST \\
\hline One vessel & $8(25)$ & $8(10)$ & $2(11)$ & $14(54)$ \\
Two vessel & $4(12.5)$ & $29(36)$ & $6(33)$ & $8(31)$ \\
Three vessel & $20(62.5)$ & $43(54)$ & $10(56)$ & $4(15)$ \\
Total & $32(100)$ & $80(100)$ & $18(100)$ & $26(100)$ \\
\hline
\end{tabular}

Figures in parentheses are percentages.

in patients who complained of shortness of breath (24/50: 48\%).

Table 1 shows that all four exercise induced electrocardiographic signs could be found in association with both anterior and inferior infarction. There were no significant differences in the extent of coronary disease between patients with exercise induced ST segment elevation and those with ST segment elevation plus depression or those with ST segment depression alone ( $p>0.05)$; patients without exercise induced ST segment changes had fewer coronary arteries involved than those who developed ST segment changes $(p<0.05)$ (Table 4$)$. Six patients $(12 \%)$ with exercise induced ST segment elevation had a left ventricular aneurysm demonstrated at angiography; this compares with eight (8\%) patients without exercise induced ST segment elevation ( $p>0.05)$.

Analysis of the 18 patients with both ST segment elevation and ST segment depression showed that in eight patients ST segment depression occurred on the opposite wall to the site of infarction. These patients did not differ from the other 10 in terms of symptoms or coronary disease (Table 5).

Table 5 Symptoms and extent of coronary disease in eight patients with ST segment depression located away from infarction and 10 patients with ST segment depression adjacent to infarction

\begin{tabular}{lll}
\hline & $\begin{array}{l}\text { ST away from } \\
\text { infarction }\end{array}$ & $\begin{array}{l}\text { ST adjacent to } \\
\text { infarction }\end{array}$ \\
\hline Angina & 4 & 8 \\
Dyspnoea & 5 & 4 \\
Three vessel disease & 4 & 6 \\
Two vessel disease & 4 & 2 \\
One vessel disease & 0 & 2 \\
\hline
\end{tabular}

Table 6 Correct prediction of coronary anatomy from site of precordial electrocardiographic changes

\begin{tabular}{llll}
\hline & $S T \uparrow$ & $S T \downarrow$ & $S T \uparrow+S T \downarrow$ \\
\hline One vessel & $5 / 8(63)$ & $6 / 8(75)$ & $1 / 2(50)$ \\
Two vessel & $3 / 4(75)$ & $13 / 29(45)$ & $4 / 6(67)$ \\
Three vessel & $5 / 20(25)$ & $6 / 43(14)$ & $7 / 10(70)$ \\
\hline
\end{tabular}

Figures in parentheses are percentages.
Table 7 Results of coronary artery bypass graft surgery in 19 patients with exercise induced ST segment elevation

\begin{tabular}{lll}
\hline Postoperative angina & $\begin{array}{l}\text { Postoperative ST segment } \\
\text { elevation }\end{array}$ \\
\cline { 2 - 3 } & Present & Absent \\
\hline Present & 6 & 1 \\
Absent & 1 & 11 \\
\hline
\end{tabular}

SITE OF ELECTROCARDIOGRAPHIC ABNORMALITIES AND CORONARY ANATOMY

Table 6 shows the prediction of coronary anatomy from the site of precordial electrocardiographic abnormalities. In these circumstances (that is patients with previous infarction) it was not possible reliably to predict the site or extent of coronary disease from the site of electrocardiographic changes.

\section{CORONARY ARTERY BYPASS GRAFT SURGERY}

Nineteen patients with exercise induced ST segment elevation alone and angina pectoris underwent myocardial revascularisation and postoperative arteriography. Table 7 shows the pre and postoperative clinical and exercise electrocardiographic data. In 11 of the 19 patients there was complete abolition of the exercise induced ST segment elevation after surgery; this was in association (in 11 patients) with patent grafts and relief of chest pain six months later.

\section{Discussion}

We have described the results of exercise testing and coronary artery bypass graft surgery on exercise induced ST segment elevation in patients with previous myocardial infarction.

Exercise induced ST segment elevation in patients with previous myocardial infarction was found to be common, occurring in $32 \%$ of patients both with and without accompanying ST segment depression. ST segment elevation occurred entirely in leads with $Q$ waves, a finding noted by others. ${ }^{8}$ Earlier reports that exercise induced ST segment elevation was uncommon probably result from the practice of using a single lead for exercise testing. ${ }^{9}$ ST segment elevation 
in the absence of previous infarction, however, is rare. ${ }^{89}$

Exercise induced ST segment elevation occurred both with and without ST segment depression. In this study, unlike earlier workers, we have tried to understand the significance of the ST segment elevation by comparing the clinical and angiographic findings of those with this electrocardiographic sign with patients with both ST segment elevation and depression, those with ST segment depression alone, and those without ST segment changes.

Unlike many previous workers we found angina to be a frequent symptom in patients with ST segment elevation whether or not there was accompanying ST segment depression. ${ }^{810}$ The differences in the various studies probably reflect selection criteria. Most of our patients were investigated because they had chest pain, at least as a part of their symptom complex. Our study differs from others in that we have compared the symptoms noted on exercise testing with the different electrocardiographic responses. In particular, angina was infrequent only when there were no ST segment changes. This suggests that the development of exercise induced ST segment elevation even in the absence of ST segment depression does reflect myocardial ischaemia in a proportion of patients. Important confirmation of this was found when the effects of venous graft surgery were studied in those patients who developed ST segment elevation. A successful operation was associated in the majority of patients with abolition of both angina and the exercise induced ST segment elevation. This occurred in the absence of any improvement in left ventricular function seen at angiography. A similar finding was noted in the single case cited by Hegge et al. ${ }^{11}$

The coexistence of both ST segment elevation and ST segment depression has led some to postulate that these two electrocardiographic signs are merely reciprocal changes. ${ }^{11}$ Though the use of a precordial mapping system has allowed us to study the changes that occur over the front of the chest, it is still possible that ST segment elevation that occurs in isolation on the front of the chest may reflect ST segment depression on the back. In a single patient with ST segment elevation occurring after exercise we have precordially mapped the back as well as the front of the chest and were unable to identify any leads with ST segment depression.

Perhaps the most frequent explanation of ST segment elevation that occurs in leads with $Q$ waves is that this is an electrocardiographic manifestation of left ventricular dyskinesia.1213 Though isotope studies appear to provide some support for this hypothesis, ${ }^{13} 14$ they do not provide an adequate electrical explanation. Normally subendocardial ischaemia manifests itself as ST segment depression;
ST segment elevation is usually considered to reflect transmural ischaemia. ${ }^{15}$ The "electrical window" of an old infarct, however, provides what is functionally a cavity lead giving a $Q$ wave, ${ }^{16}$ and thus in the presence of subendocardial ischaemia it may be expected that ST segment elevation would be recorded. ${ }^{16}$

Left ventricular dyskinesia was found in the vast majority (all but four patients) of our patients; in contrast, left ventricular aneurysm was seen rarely. No differences were found in the left ventricular function of those patients with and without exercise induced ST segment elevation. This, of course, must be considered in the context of a group of patients almost all of whom have some abnormality of ventricular function.

In contrast, patients with exercise induced ST segment elevation were found frequently to have extensive coronary disease. In this respect ST segment elevation did not differ from ST segment depression alone or ST segment elevation plus ST segment depression. We were also unable to distinguish in terms of symptoms or coronary disease between ST segment elevation with adjacent ST segment depression and ST segment elevation with ST segment depression away from the site of infarction. This last should be interpreted with caution since there were only 18 patients with exercise induced ST segment elevation plus depression. Patients with previous myocardial infarction but without ST segment changes were those most likely to have less severe coronary disease often involving only one vessel. It was, however, not possible to predict the site of coronary disease from the exercise test.

Although the genesis of exercise induced ST segment elevation still remains uncertain, this study suggests that in a substantial proportion myocardial ischaemia plays an important role, whether or not the ST segment elevation is accompanied by ST segment depression. For practical purposes this electrocardiographic sign should not be considered in any way different from ST segment depression in patients with previous myocardial infarction, since their clinical features, extent of coronary disease, and left ventricular function abnormalities do not differ.

\section{References}

1 Granath A, Södermark T, Winge T, Volpe U, Zetterquist S. Early work load tests for evaluation of long-term prognosis of acute myocardial infarction. $\mathrm{Br}$ Heart $\mathcal{F}$ 1977; 39: 758-63.

2 Castellanet MJ, Greenberg PS, Ellestad MH. Comparison of ST segment changes on exercise testing with angiographic findings in patients with prior myocardial infarction. Am f Cardiol 1978; 42: 29-35.

3 DeBusk RF, Davidson DM, Houston N, Fitzgerald J. Serial ambulatory electrocardiography and treadmill 
exercise testing after uncomplicated myocardial infarction. Am F Cardiol 1980; 45: 547-54.

4 Théroux P, Waters DD, Halphen C, Debaisieux JC, Mizgala HF. Prognostic value of exercise testing soon after myocardial infarction. $N$ Engl $\mathcal{F}$ Med 1979; 301: 341-5.

5 Fox KM, Selwyn AP, Shillingford JP. A method for praecordial surface mapping of the exercise electrocardiogram. Br Heart $f$ 1978; 40: 1339-43.

6 Fox KM, Selwyn AP, Shillingford JP. Precordial exercise mapping: improved diagnosis of coronary artery disease. $\mathrm{Br}$ Med f 1978; ii: 1596-98.

7 Fox KM, Selwyn AP, Oakley D, Shillingford JP. Relation between the precordial projection of ST segment changes after exercise and coronary angiographic findings. Am $\mathcal{Y}$ Cardiol 1979; 44: 1068-75.

8 de Feyter PJ, Majid PA, van Eenige MJ, Wardeh R, Wempe FN, Roos JP. Clinical significance of exerciseinduced ST segment elevation. Br Heart $\mathcal{F}$ 1981; 46: 8492.

9 Fortuin NJ, Friesinger GC. Exercise induced ST segment elevation. Clinical, electrocardiographic and arteriographic studies in twelve patients. Am $\mathcal{F}$ Med 1970; 49: 459-64.

10 Weiner DA, McCabe C, Klein MD, Ryan TJ. ST segment changes post-infarction: predictive value for multivessel coronary disease and left ventricular aneurysm. Circulation 1978; 58: 887-91.

11 Hegge FN, Tuna N, Burchell HB. Coronary arterio- graphic findings in patients with axis shifts or ST segment elevations on exercise-stress testing. Am Heart $f$ 1973; 86: 603-15.

12 Chahine RA, Raizner AE, Ishimori $T$. The clinical significance of exercise induced ST segment elevation. Circulation 1976; 54: 209-13.

13 Selwyn AP, Fox KM, Forse G, Pratt T, Steiner R. An investigation in patients with previous myocardial infarction who present with chest pain. Circulation 1981; 64: $1156-62$.

14 Lahiri A, Balasubramanian V, Millar Craig MW, Crawley J, Raftery EB. Exercise induced ST segment elevation. Electrocardiographic, angiographic, and scintigraphic evaluation. Br Heart $\mathcal{f}$ 1980; 43: 582-8.

15 Prinzmetal M, Toyoshima H, Ekmekci A, Mizuno Y, Nagaya T. Myocardial ischemia. Nature of ischemic electrocardiographic patterns in the mammalian ventricle as determined by intracellular electrographic and metabolic changes. Am f Cardiol 1961; 8: 493-503.

16 Bayley RH. An interpretation of the injury and the ischemic effects of myocardial infarction in accordance with the laws which determine the flow of electric currents in homogeneous volume conductors, and in accordance with relevant pathologic changes. Am Heart $\mathcal{f}$ 1942; 24: 514-28.

Requests for reprints to Dr K M Fox, National Heart Hospital, Westmoreland Street, London W1M 8BA. 